\title{
El famoso gay en prensa. Reivindicación y derecho a través de la información
}

\author{
Ramón NAVARRETE-GALIANO RODRÍGUEZ \\ Universidad de Sevilla \\ Galiano@us.es
}

Recibido: $23 / 05 / 2012$

Aceptado: 09/09/2013

\begin{abstract}
Resumen
La aparición en los medios de comunicación de hombres homosexuales ha supuesto un revulsivo en la sociedad española en los últimos 15 años, en lo que a la reivindicación de los derechos del colectivo gay se refiere. La salida voluntaria del armario de jueces, presentadores de televisión, empresarios vinculados con la denominada jet-set, políticos, ha aparecido en la agenda de los medios de comunicación de forma continuada y tratada con un rigor y seriedad que ha supuesto, además de información sobre determinados personajes, el poder ofrecer una reclamación de visibilidad e integración de este colectivo minoritario. Es decir, lo que en un principio suponía una entrevista para las páginas de sociedad, dada la forma en que se trataba el tema, se transformaba en una forma de cuestionar la sociedad actual y analizar la realidad del colectivo homosexual.
\end{abstract}

Palabras clave: Gays, entrevistas en prensa, información y reivindicación, defensa de derechos, homosexualidad.

\section{The famous gay in the press. Claim and Right through the information}

\begin{abstract}
The appearance in the media of gay men has been a salutary lesson in Spanish society over the past 15 years, as far as the claim of gay rights is concerned. The voluntary departure of the closet of judges, TV presenters, businessmen associated with the so-called jet-set, politicians, has appeared on the agenda of the media continuously and treated with a rigor and seriousness that has been also information on certain characters, a claim to offer visibility and integration of this minority group. That is, what initially supposed an interview for the society pages, given the way the issue was, was transformed into a form of questioning today's society and analyze the reality of homosexuals.
\end{abstract}

Keywords: Gay, interviews in press, information and claim, defense of rights, homosexuality.

\section{Referencia normalizada}

NAVARRETE-GALIANO RODRÍGUEZ, Ramón (2013): "El famoso gay en prensa. Reivindicación y derecho, a través de la información". Estudios sobre el Mensaje Periodístico. Vol. 19, Núm. 2 (julio-diciembre), págs.: 805-812. Madrid, Servicio de Publicaciones de la Universidad Complutense.

Sumario: 1. Introducción. 2. Nuevo tratamiento de lo gay. 3. La visibilidad del gay en los medios. 4. La prensa escrita. 5. Entrevistas realizadas. 6. Otra visibilidad de lo gay en prensa. 7. La ética informativa. 8. Conclusiones. 9. Referencias.

\section{Introducción}

El Viernes Santo de 2012 ha quedado como un ejemplo de la utilización que la Iglesia Oficial Católica hace de los medios de comunicación para reivindicar su ideario y discurso. En concreto la homilía del obispo de Alcalá, Reig Plá, emitida por la segunda cadena de RTVE, quien fue tildado de homófobo y reaccionario, ha levantado una gran polémica, dado que utilizó un medio público para exponer una doctrina que hasta el momento transmitían en cartas pastorales o desde los púlpitos de la iglesias españolas. El obispo era muy consciente de la repercusión que iban a tener sus pala- 
bras, ya que se trataba de una transmisión estatal, y además de la única de esas características, un oficio religioso, que se iba a emitir por una cadena nacional. Aprovechar las cámaras y los micrófonos para emitir su ideario, da cuenta de cómo la institución eclesiástica ha comprendido la importancia que los medios de comunicación han tenido y tienen para la reivindicación y derechos del colectivo gay en España, por ello que mejor que utilizar sus mismas armas, para adoctrinar a los correligionarios del obispo.

Desde hace unos 15 años la visibilidad del gay, en los medios de comunicación ha supuesto un cambio de postulados y mensaje. La agenda de los medios de comunicación, preferentemente la prensa escrita, ha abordado con rigor este tipo de información, sobre todo cuando se ha tratado de entrevistas a personajes populares o famosos, que además de servir como ejemplo para gays ocultos, han puesto sobre la mesa las necesidades y derechos de un colectivo, marginados históricamente. Además de ofrecer información sobre la vida del personaje, el medio difundía las necesidades del colectivo y sus postulados reivindicativos. Atrás quedaban informaciones sensacionalistas, o vinculando la homosexualidad masculina con el lumpen, la delincuencia y la noche.

\section{Nuevo tratamiento de lo gay}

En la actualidad al colectivo gay tiene un tratamiento serio y honesto en el conjunto de medios de comunicación españoles. Un hecho determinante fue el tratamiento que se dio al famoso Caso Arny de Sevilla, en el que el juzgado de instrucción no 13 de Sevi1la inició un sumario donde se llegó a investigar hasta a 59 hombres, cuya lista de imputados se publicó en casi todos los medios de comunicación desde el principio, por lo que se violó el derecho al honor y produciendo indefensión en los acusados, la mayoría de los cuales resultarían posteriormente inocentes. Las defensas alegaron que se vulneraron derechos fundamentales y que los acusados sufrieron un juicio paralelo en los medios de comunicación donde se violó de forma sistemática la presunción de inocencia, el secreto de sumario y su derecho al honor. La sentencia desmanteló una amplia red de rumores y daños morales causados por los medios de comunicación a los implicados. Al final la mayoría de los acusados, treinta y dos de los cuarenta y siete imputados, resultaron absueltos en la sentencia y solo ingresaron en prisión dos de los dieciséis condenados. Recordemos que entre los imputados se encontraban el presentador Jesús Vázquez, el cantante Javier Gurruchaga, y el humorista Jorge Cadaval.

Este caso supuso una inflexión en lo que al tratamiento de estos temas había que hacer, incluso algunos profesionales de la comunicación televisiva, sufrieron una merma en su credibilidad por la forma sensacionalista en que trataron el tema. Algo muy similar a lo que sucedió con el planteamiento de otros sucesos, como fue el crimen de Alcácer, que desgastó notablemente a periodistas y líderes de opinión televisiva. En la actualidad sigue habiendo, por desgracia casos de este tipo, pero la información dada ha sido diferente. Valga como ejemplo el conocido como caso de Marta del Castillo en Sevilla.

Por ello es evidente que ha habido una transformación en la sociedad española, en lo que se refiere al respeto de los derechos del colectivo gay, y en este cambio de mentalidad ha tenido mucho que ver la prensa escrita en la forma rigurosa, alejada de cual- 
quier atisbo de sensacionalismo con que ha tratado este tema. Un ejemplo es la información que el diario El País, ofrecía el 17 de abril de 2012 sobre la respuesta de colectivos gays a la homilía y posteriores declaraciones del prelado de Alcalá:

Representantes de la Federación Estatal de Lesbianas, Gays, Transexuales y Bisexuales (FELGTB) y del Colectivo de Gays de Madrid (COGAM) han presentado a las once y media de la mañana una denuncia conjunta ante la Fiscalía Provincial de Madrid contra las declaraciones del obispo de Alcalá de Henares, Juan Antonio Reig Plá, por "provocación al odio, la violencia y la discriminación" a los gais. La denuncia se basa en un artículo del Código Penal y en los valores constitucionales -en concreto, cita dos artículos de la Constitución-. "Es hora de dejar de quejarse y de pasar a la acción" para pedir responsabilidades al "reincidente" Reig Pla, que ayer dijo que la homosexualidad tiene cura, han explicado los denunciantes a la cadena SER a las puertas de la fiscalía.

Según estas asociaciones, en su polémica homilía de Viernes Santo, retransmitida en directo por La 2 de TVE, el prelado incurrió presuntamente en "un delito de Provocación a la Discriminación y al Odio, contenido en el artículo 510 del Código Penal" (El Pais, Agencias, secc. Madrid, 17 de abril de 2012).

La información ofrece las declaraciones, la justificación y argumentación del colectivo, sustentada en la Carta Magna Española y en el Código Penal, o sea, alejándose de cualquier reivindicación maniqueísta, y argumentándolo razonadamente en base a unos documentos que defienden el derecho de los ciudadanos a ejercer su libertad.

La situación no quedó ahí ya que el viernes 11 de mayo de 2012 el mismo diario presentaba el siguiente titular "Un juez estudia si Reig Plà delinquió al hablar de gais". La información, firmada por Tonio Calleja, se iniciaba así:

El titular del Juzgado de Instrucción número 6 de Alcalá de Henares, Antonio Cervera, ha solicitado a la dirección de Televisión Española (RTVE) que le envíe "a la mayor brevedad posible" en formato DVD la grabación de la misa celebrada en el municipio madrileño el pasado 6 de abril.

El juez ha tomado esta determinación tras la denuncia presentada por la asociación Preeminencia del derecho. Y asegura el periodista que el juez quiere comprobar con la grabación si el obispo dijo "las palabras señaladas en la denuncia".

La citada asociación, a través de su portavoz, José Luis Mazón, asegura al diario que "el juez abre diligencias previas, lo que significa que aprecia indicios de delito, porque de otro modo habría archivado sin trámite la denuncia" (El País, Tonio Calleja, 11 de mayo de 2012)

\section{La visibilidad del gay en los medios}

La presencia de un personaje famoso, declarado abiertamente gay, tuvo un antes y un después con la aparición de Boris Izaguirre, en el programa de Javier Sardá, Crónicas Marcianas, en la cadena pública Tele 5. Izaguirre hizo visible al hombre homosexual, en este caso con determinado amaneramiento. Fue el primer caso popular y conocido en España, y contó con un apoyo y reconocimiento del público, ya que la sociedad española empezaba a madurar y respetar a su modo, un tanto forzado, la opción sexual de cada uno, de su capacidad expresiva e intelectual. Izaguirre destacaba por su inteligencia y creatividad, por su chispa personal y con maneras un tanto exa- 
geradas que resultaban simpáticas al gran público. Quizás esa desmedida simpatía era una forma de alejar suspicacias o presentar una cara más amable del colectivo. Es decir, se procuraba acercar al gay a la sociedad, desvinculándolo de mundo marginal al que se había asociado en España durante muchos años. El escritor Javier Marías, sin concretar ningún nombre, en uno de sus artículos de opinión de El País Semanal (2904-2012) apuntaba este aspecto, y venía a concretar lo apuntado más arriba, ya que señalaba que algunos de estos personajes habían mostrado de forma estentórea y exagerada su homosexualidad para ganarse la simpatía de la sociedad:

La aceptación de los homosexuales ha sido una de las conquistas que se han producido en España con mayor naturalidad, tras décadas, no se olvide (todas las del franquismo, como mínimo), en las que estuvieron perseguidos, vivieron en las catacumbas y muchos de ellos sufrieron palizas y cárcel, sólo por su condición. Es llamativo el ensañamiento que han padecido a lo largo de siglos, aquí y en otros lugares, cuando nunca han constituido una minoría violenta ni amenazadora, antes al contrario, ha solido ser pacífica y respetuosa. (Hablo como colectivo, claro está: en todos los ámbitos hay individuos agresivos y malintencionados.)

Bien es verdad que esa aceptación ha tenido lugar mediante el pago de algunos peajes por parte de los homosexuales, peajes que bastantes de ellos encuentran humillantes (probablemente con razón), pero que en todo caso denotan habilidad. Los gays españoles se supieron hacer "simpáticos" y resultaron "graciosos" para la gran mayoría de la sociedad. No pocos se sometieron a un cierto estereotipo: individuos festivos y desenfadados, a menudo ingeniosos y exagerados, con una malicia y un descaro refrescantes que no llegaban a ofender a nadie. Tanto los programas como las series de televisión se llenaron de personajes así, hasta el punto de hacerse cargante la reiteración y de acercarse demasiado al tópico y a la caricatura. Pero esa dimensión "familiar" del gay, ese despojamiento de los aspectos siniestros o monstruosos con que tradicionalmente se lo quiso presentar, ayudó no poco -guste o no, y comprendo que no- a su "normalización" (Javier Marías, "Lo que ya no se tendría que decir", El País Semanal, 29 de abril de 2012).

Izaguirre hizo bastante por la reivindicación de los derechos del colectivo gay, al igual que ha hecho el presentador de televisión Jorge Javier Vázquez: al hacer visible su vida íntima han normalizado aspectos ajenos para la mayoría de la sociedad. El hecho de que estos gays hayan hecho pública su vida ha servido para que una inmensa parte de la población que sigue esos programas haya asimilado la homosexualidad. Algo impensable hace 15 años, cuando la mayoría de los gays famosos estaban amarizados. Distinto era el caso de algunos escritores, pero claro, este colectivo es una élite minoritaria. Solo podíamos excluir de ese grupo el ejemplo de Terenci Moix, escritor, y muy popular, que hizo de su homosexualidad una reivindicación continua.

Por ello, aunque en un primer momento el amaneramiento de Boris Izaguirre resultaba singular, poco a poco la sociedad española comprendió que detrás de aquellas maneras exageradas había un hombre con una sólida formación, con unas opiniones acertadas y, lo que es más, informadas y justificadas, que le otorgaron el respeto de la mayoría de los televidentes españoles.

Es decir, en la televisión la presencia del gay ha estado vinculado un tanto al espectáculo mediático pero es cierto que ha servido para dar cara a algunos de ese colectivo, lo que ha supuesto normalizar al resto. Además estos presentadores o 
animadores han demostrado una categoría profesional que ha afianzado el respeto del colectivo mayoritario de seguidores de esos programas.

Junto a ello también hemos de de tener en cuenta la visibilidad del gay a través de las series de ficción, como veremos más adelante. El diario El País, en su sección sobre televisión del 21 de mayo de 2012, titulaba así una información: "La televisión como vehículo de normalidad gay en Estados Unidos"; y como subtítulo: "Las series representan la avanzadilla de la lucha contra la homofobia". En el artículo que ocupaba más de media página se hacia una revisión de la presencia de personajes homosexuales en series de televisión estadounidense y como estos han contribuido a normalizar este colectivo ante la sociedad estadounidense, y a hacerla avanzar a la hora de reconocer sus derechos. En la información se afirmaba: "para declarar que la nación estaba lista para el matrimonio gay, el vicepresidente de Estados Unidos no solo aportó razones políticas o sociológicas. Recurrió también a la televisión. "Creo que Will \& Grace probablemente hizo más por educar al público norteamericano que nadie hasta hora", dijo el 6 de mayo Joe Biden". En concreto en esta serie hay dos protagonistas gays que son seguidos por millones de televidentes. Identificarse a través de la ficción con determinadas personas facilita la aceptación de colectivos, como el homosexual, hasta ahora discriminados.

\section{La prensa escrita. El País}

Junto a la presencia pública del gay en la televisión otros medios también han incidido en hacer visible al colectivo y en normalizar una opción que, paralelamente la sociedad civil, iba reconociendo los derechos del colectivo gay como el matrimonio homosexual. Junto a esos medios, que trataban los temas con rigor en sus páginas, alejadas de cualquier sensacionalismo, surgió la revista Zero (1998-2009).

Zero fue una publicación mensual destinada a un público gay, con contenidos lúdicos, pero también con una apuesta reivindicativa clara y tajante, como fueron sus portadas con sendos militar y sacerdote hablando de su homosexualidad, o personajes famosos como el bailarín Nacho Dato que también lo hizo. Es decir Zero sacó a los quioscos una visión de la homosexualidad reivindicativa, digna, con un planteamiento nada escabroso ni sensacionalista. La revista se exponía en los quioscos junto a las publicaciones habituales, lo que le posibilitó llegar a un gran público (y no solo al lector homosexual) que pudo conocer sus contenidos y las reivindicaciones de sus páginas. Asimismo la prensa escrita generalista ha hecho visibles a muchos gays famosos, vinculados con la hostelería, la judicatura, la política o el periodismo. De estos últimos de sobra son conocidos los casos de Jesús Vázquez o Jorge Javier Vázquez que hacen continua reivindicación de su opción sexual. También en ocasiones se ha vinculado a destacados gays con un denominado poder rosa, aunque quizás habrá que entenderlo más como un reconocimiento a la posición que los homosexuales tienen dentro de una sociedad democrática, alejados de los estereotipos tradicionales que vinculaban a un gay con determinados trabajos afines con la estética, la moda y el cuidado de las mujeres.

La prensa ha abordado estos casos con rigor, al igual que lo ha hecho con otros casos de la actualidad internacional, como sucedió en el diario El País (12-05-12) en 
la páginas de la sección "Revista Sábado", en la que bajo el titular "La conciencia de Barack Obama sale del armario" se explica la posición favorable del presidente estadounidense al matrimonio homosexual, así como la presencia de Jeremy Bernard, un reconocido gay, al frente de la Secretaria Social de la Casa Blanca. El tratamiento de la información destacaba cómo Obama equipara el reconocimiento del matrimonio entre personas del mismo sexo con el que en los años sesenta se hizo del reconocimiento de los derechos civiles de los negros.

Ese rigor en la información ha ayudado a que la sociedad visualice esta opción sexual de otra forma a como se había planteado anteriormente. También han tenido mucha importancia las entrevistas a destacados personajes de la vida política o la judicatura. En esas entrevistas, donde se destaca su labor profesional, también se reivindica su vida íntima, sin caer en sensacionalismo ni victimismos. Los entrevistados y el periodista han rechazado de pleno caer en un tono vulgar o resentido, Si analizamos varias entrevistas realizadas a Iñigo Lamarca o Fernando Grande Marlaska comprendemos este tratamiento. Se ha buscado hablar de una cuestión normalizándola, rehuyendo sin ambages el sensacionalismo o el amarillismo. Presentándolo como algo común. Estudios sobre el tratamiento que se ha de dar a esta información como el realizado por el profesor Juan Carlos Suárez, de la Universidad de Sevilla, que realizó una encuesta entre periodistas andaluces, dan cuenta de esta tendencia. Así en ese texto (Suárez, 2011: 63) observamos que el 33,6\% por ciento de los encuestados considera que la información sobre homosexuales ha de de tener un tratamiento "bastante" especial, y el 5,8\% considera que "mucho", frente al 37,7\% y el 22,9\%, que cree que ha de tener "poco" o "nada" de tratamiento especial. Es decir el 60,6\% opina que el colectivo gay no necesita un tratamiento distinto. Esta estadística contrasta con la ofrecida en la misma publicación acerca del tratamiento de la información sobre los inmigrantes, donde el 14,3\% del sector periodístico cree que merece un tratamiento muy especial ("mucho"); un 46,6\% "bastante", un 23,8\% "poco" y un 15,2 \% "nada". O sobre los ancianos, donde el "mucho" tiene un 16, 2\%, el "bastante" un 41,4\%, el "poco" un $28,4 \%$ y el "nada" un $14,0 \%$.

Aunque puede decirse que la mayoría de la prensa española ha ejercido una gran responsabilidad en el tratamiento de las informaciones sobre el colectivo gay, por lo que ha ayudado enormemente a su socialización e integración, ha sido el diario $E l$ País el más activo en este cometido. Son absolutamente destacables las entrevistas que ha publicado este diario a destacados personajes de la sociedad española que quisieron hacer pública su homosexualidad, como la entrevista de Sol Alameda a Iñigo Lamarca, Defensor del Pueblo Vasco, el 24 de octubre de 2004, titulada "Un luchador por la igualdad". Y la de Rosa Montero al juez de la Audiencia Nacional Fernando Grande-Marlaska, el 11 de junio de 2006, titulada "En el ojo del huracán". Ambas entrevistas son un modelo de buena escritura y de una admirable conversación en la que surge con soltura y normalidad el aspecto de la homosexualidad de ambos personajes, con confesiones valientes sobre su vida con una profundidad y naturalidad realmente encomiables.

El País también ha dedicado páginas a reportajes cuya función principal ha sido la de lograr la plena integración social de los homosexuales, como por ejemplo el cui- 
dado relato de Luz Sánchez Mellado titulado "Una generación sin armario" (8 de febrero de 2009), del que extraemos el significativo comienzo:

Son los primeros que no se esconden. Han crecido con referentes y derechos. Salen del armario cada vez más, cada vez antes. Los nuevos gays y lesbianas viven como sienten. No es fácil. Sufren. Pero prefieren plantarle cara al mundo que perderse su juventud.

Es posible que los peces gordos de Telecinco no se hayan enterado. Pero Macarena, Maca, Fernández, pediatra de Hospital Central, la teleserie decana de la casa, es un icono para ciertas chicas españolas. Maca es guapa. Competente. Carismática. Y lesbiana. Rocío Fernández no se pierde un capítulo. No los mira en la tele de su casa, donde vive con sus padres. Prefiere verlos sola. Por eso se los baja de Internet. Fue en cualquier parte, con el portátil acunado en el regazo, donde la adolescente Rocío visualizó cómo quería ser de mayor.

Gracias a la historia de amor entre Maca y Esther vi que es posible amar a otras mujeres, casarse, ser madre con otra, tener éxito y respeto social. Que esto es natural y bonito, que no eres un bicho raro ni tienes que sufrir por ello. Maca me ayudó a salir de mi propio armario, el de mi familia y el del mundo".

Rocío tiene 21 años, estudia Ingeniería de Obras Públicas y es lesbiana. No lo va pregonando. Tampoco lo oculta. Vive como siente, punto. Ellas han tenido a Maca. O a Diana, la devora mujeres de Siete vidas. O a Lindsay Lohan, ex novia adolescente de América, hoy pareja de la dj Samantha Ronson. Los chicos, a Fidel, el chaval hipersensible de Aída. Al comunicador estrella Jesús Vázquez. O al mismísimo Fernando Grande-Marlaska, juez de la Audiencia Nacional, aconsejando en las vallas el uso del preservativo a los hombres que, como él, tienen relaciones sexuales con otros hombres.

Todos, ellos y ellas, han visto el cielo abrirse ante sus ojos con sólo teclear la palabra gay o lesbiana seguida del nombre de su ciudad en Internet. La nueva generación de homosexuales españoles ha crecido con referentes. Espejos donde mirarse. Ejemplos en los que reconocerse. Y derechos adquiridos. Rocío estrenó su mayoría de edad en 2005, el año en que se aprobó la ley de matrimonio de personas del mismo sexo. El cuarentón Marlaska no tuvo esa suerte.

Su señoría lo confesaba ante los chavales de un instituto madrileño. "Tuve clara mi orientación sexual desde muy joven, pero perdí 25 años de mi vida afectiva por la ley del silencio. Hasta los 35 años no lo reconocí ante el mundo". Marlaska y muchos de sus coetáneos han pasado su juventud apolillándose en el ropero. Entre otras cosas porque hasta los ochenta no se derogó la Ley de Peligrosidad Social, que consideraba delincuentes a los homosexuales. Algunos, habituados a una confortable reclusión privada o reprimidos por la intolerancia social, han elegido quedarse a vivir dentro. La generación de Rocío no está dispuesta a perderse nada.

\section{Conclusiones}

La responsabilidad y la ética de los medios de comunicación se mide por sus continuas acciones, muchas de ellas destinadas no solo a informar sino a formar persiguiendo un bien común como la paz, la buena convivencia, el respeto a las personas sin distinción de clase, sexo, opción sexual y cualesquiera otras opciones elegidas libremente y respetuosas con los mandatos constitucionales. Al leer los textos descritos encontramos que se ha hecho patente lo que se podría considerar una ética de la comunicación. Una ética especial que permite alcanzar el fin último de la acción moral ya sea de índole individual o social. 
El periodista, por medio de la ética individual, regula su conciencia profesional, lo que le permite desarrollar una responsabilidad de alto nivel. El periodista desarrollará una ética de la información por medio de dos clases de ética: la individual y la social. Por la primera el periodista ha de contar con una esmerada formación que le llevará a realizar su trabajo de forma rigurosa; y por la segunda logrará una información veraz y objetiva. Porque la finalidad de la profesión periodística recae éticamente sobre un objetivo incuestionable, que es el respeto a la dignidad de la persona. De tal forma que para alcanzar ese nivel ético, el periodista tiene que alejarse "del punto de vista unilateral, tendencioso, ambiguo y de ocultamiento de la realidad...necesita poseer una amplia escala de argumentos, datos o ideas para defender o destacar la verdad y la justicia, y para distinguir perfectamente las causas y las consecuencias de un hecho y un proceso" (Vázquez, 1983: 148).

El periodista ha de poder manifestar una conciencia personal, desarrollar su libertad en la creación y mostrar actitud crítica para erradicar la manipulación colectiva o la pasividad informativa, según apuntan especialistas (Suárez, 1998: 97).

El tratamiento de la homosexualidad ofrecido en la prensa e incluso en determinados programas de entretenimiento o espectáculo de varias cadenas españolas de televisión ha contribuido a normalizar, desde una visibilidad reivindicativa, un colectivo tradicionalmente denostado y obligado a ocultarse. Por ello la sociedad española ha evolucionado notablemente en el respeto de los derechos de colectivo homosexual y a la igualación en derechos y libertades de las parejas gays. Los medios de comunicación españoles han sido decisivos para la construcción y vertebración del estado democrático español. Han demostrado también que la información tiene un poder reivindicativo e integrador y que puede ejercerse.

\section{Referencias}

ALAMEDA, Sol (2004): “Un luchador por la igualdad". Entrevista a Iñigo Lamarca, Defensor del Pueblo Vasco. El País Semanal, 24 de octubre, en: http://elpais.com/diario/2004/10/24/eps/1098599217_850215.html

MARÍAS, Javier (2012): "Lo que ya no se tendría que decir". El País Semanal, 29 de abril de 2012. También en el blog de J. Marías "La zona fantasma": http://javiermariasblog.wordpress.com/2012/04/

MONTERO, Rosa (2006): "En el ojo del huracán". Entrevista al juez de la Audiencia Nacional Fernando Grande-Marlaska. El País, 11 de junio, en: http://elpais.com/diario/2006/06/11/eps/1150007214_850215.html

SÁNCHEZ MELLADO, Luz (2009): "La generación sin armario". Reportaje. El País, 8 de febrero, en: http://elpais.com/diario/2009/02/08/eps/1234078015_850215.html

SUÁREZ, Juan Carlos (1998): Principios de ética profesional. Madrid, Editorial Anaya.

SUÁREZ, Juan Carlos (2011): Medios de Comunicación y autocontrol. Madrid, Dykinson.

VÁZQUEZ, Francisco (1983): Fundamentos de ética informativa. Madrid, Forja. 